Article

\title{
Synthesis and Biological Evaluation of Liguzinediol Mono- and Dual Ester Prodrugs as Promising Inotropic Agents
}

\author{
Jing Zhang, Wei Li *, Hong-Mei Wen, Hao-Hao Zhu, Tian-Lin Wang, Dong Cheng, \\ Kun-Di Yang and Yu-Qing Chen
}

School of Pharmacy, Nanjing University of Chinese Medicine, 138 Xianlin Road, Nanjing 210023, Jiangsu, China; E-Mails: zjczjhappy@163.com (J.Z.); njwhm@126.com (H.-M.W.); zhux58@163.com (H.-H.Z.); cpuwtl@gmail.com (T.-L.W.); dillon1987@sina.com (D.C.); aragron135@163.com (K.-D.Y.); drcoreychen@gmail.com (Y.-Q.C.)

* Author to whom correspondence should be addressed; E-Mail: liwaii@126.com or liwaii@njutcm.edu.cn; Tel.: +86-25-8679-8269.

External Editor: Derek J. McPhee

Received: 2 September 2014; in revised form: 29 October 2014 / Accepted: 29 October 2014 / Published: 5 November 2014

\begin{abstract}
The potent positive inotropic effect, together with the relatively low safety risk of liguzinediol (LZDO), relative to currently available inotropic drugs, has prompted us to intensively research and develop LZDO as a potent positive inotropic agent. In this study, to obtain LZDO alternatives for oral chronic administration, a series of long-chain fatty carboxylic mono- and dual-esters of LZDO were synthesized, and preliminarily evaluated for physicochemical properties and bioconversion. Enhanced lipophilic properties and decreased solubility of the prodrugs were observed as the side chain length increased. All esters showed conspicuous chemical stability in phosphate buffer ( $\mathrm{pH}$ 7.4). Moreover, the enzymatic hydrolysis of esters in human plasma and human liver microsomes confirmed that the majority of esters were converted to LZDO, with release profiles that varied due to the size and structure of the side chain. In vivo pharmacokinetic studies following oral administration of monopivaloyl (M5), monodecyl (M10) and monododecyl (M12) esters demonstrated the evidently extended half-lives relative to LZDO dosed alone. In particular the monopivaloyl ester M5 exhibited an optimal pharmacokinetic profile with appropriate physiochemical characteristics.
\end{abstract}


Keywords: liguzinediol; prodrug; physicochemical properties; bioconversion; pharmacokinetics

\section{Introduction}

Heart failure is a complex syndrome resulting in the abnormal pumping of blood, a major cause of morbidity and mortality in cardiovascular disease [1]. Improving cardiac contractility with orally positive inotropic agents has been an important treatment of chronic heart failure. Currently orally available positive inotropic agents in the clinic primarily include digitalis, phosphodiesterase inhibitors, and dopamine. They exert positive inotropic effects in cardiac muscle by suppressing $\mathrm{Na}^{+}-\mathrm{K}^{+}$ATPase, phosphodiesterase, and stimulating $\beta$-adrenergic receptor respectively [2]. However, these targets are also thought to be commonly related to ventricular arrhythmia and may lead to sudden death [3-6]. 2,5-Dihydroxymethyl-3,6-dimethylpyrazine (liguzinediol, LZDO, Figure 1), was found to exert markedly positive inotropic effects targeting the sarcoplasmic reticulum (SR) $\mathrm{Ca}^{2+} \mathrm{ATPase}$ to elevate SR $\mathrm{Ca}^{2+}$ transient [7]. SR $\mathrm{Ca}^{2+} \mathrm{ATPase}$ has been reported by Lipskaia as a potent therapeutic target for heart failure with good safety and applicability [8].

Figure 1. Structure of LZDO.

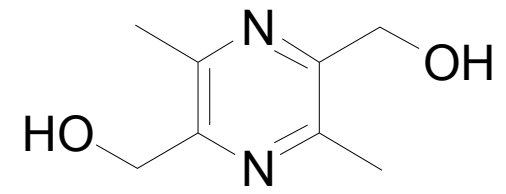

Studies in isolated hearts and diverse animal models of heart failure showed that LZDO has a markedly positive inotropic effect, and no arrhythmia was observed in extensive tests [9-13]. Further, toxicity assays proved LZDO highly safe, without acute and local toxicity [14], teratogenesis or mutagenicity. Its novel mechanism of action, potent positive inotropic efficacy, and relatively low safety risk have led to the preclinical development of LZDO as a promising patented positive inotropic agent for acute administration by injection $[15,16]$. The pharmacokinetic studies revealed that LZDO was eliminated rapidly when administrated orally or intravenously [17]. To satisfy different administration regimes in the clinic, in this work, we sought to discover novel LZDO derivatives as orally positive inotropic agents for chronic administration. Adequately long duration of action is clinically desirable for chronic administration, which could reduce frequent oral administrations and improve patient compliance. Based on studies of its pharmacokinetic mechanism the rapid disappearance of LZDO was attributed to its high polarity due to the presence of two free hydroxyl groups in the molecule [18]. Furthermore, previous structure-activity relationship studies revealed that the para-dihydroxylmethyl group of LZDO was necessary $[19,20]$. As stated in the literature, a prodrug might be considered when pharmacokinetically problematic moieties are essential requisites for biologically activity [21]. Hence, a solution followed to increase the half-life of LZDO and to offer an excellent model to deliver LZDO orally via masking of the alcohol hydroxyl groups through a prodrug strategy. Prodrugs are mostly pharmacologically inactive but can be activated by enzymes in 
body to continuously release therapeutically active metabolites, and by this means increased bioavailability, decreased metabolic inactivation, and prolonged duration of action can be achieved [22]. Nowadays, prodrugs are in a growing trend, accounting for 5\%-7\% of drugs approved worldwide in the early stages of drug discovery [23]. An extensively used approach for the development of prodrugs for active compound with hydroxyl functional groups is ester formation. Considerable efforts have already been previously made in this laboratory to research the diethylcarbonate ester prodrug of LZDO with respect to biological evaluations and pharmacokinetic studies [24]. It extended the oral half-life of LZDO to about $4 \mathrm{~h}$, still less than satisfactory for the oral chronic administration. Also, its oil nature brings about formulation problems.

In previous literature, Simões et al. reported that as the chain length of the alkoxy group is extended, the stability of pyrazinoic acid ester prodrugs in human plasma and rat liver homogenate increased [25]. In this study, the same approach was applied to appropriately regulate the bioconversion of LZDO ester prodrug by varying their side chains to realize slow-release of LZDO. Therefore, ten novel long-chain carboxyl acid mono and dual esters of LZDO were synthesized via ester linkages between the hydroxyl group of LZDO and pivaloyl chloride, capric acid, lauric acid, palmitic acid, and stearic acid. The rationale behind the mono-ester design was that the remaining hydroxyl group in conjunction with long lipophilic chains may offer adequate lipophilicity, solubility, protein affinity, and subsequently good pharmacokinetics [26]. However, they have been ignored in previous work and only regarded as synthetic intermediates of the dual esters. The idea behind designing two pivaloyl esters is based on its extensive successful ester prodrug applications (i.e., sulbactam pivoxil, cefcapene pivoxil and adefovir dipivoxil), and the hypothesis that the steric effect of its bulky molecular structure might produce favorable release of LZDO when encountering enzymes [27].

For optimization of oral LZDO prodrugs with prolonged half-life for the treatment of chronic heart failure, physicochemical properties and in vitro enzymatic bioconversion studies have been evaluated. Based upon our physicochemical and biochemical studies, monopivaloyl (M5), monodecyl (M10), and monododecyl (M12) esters of LZDO were included to further investigate the pharmacokinetics in SD rats by comparing with LZDO orally dosed alone. In this work, in vitro and in vivo studies demonstrated that an adequate lipophilic ester of LZDO could facilitate the successful prodrug delivery to prolong the duration of action of LZDO. In particular, the monopivaloyl derivative M5 exhibited superior properties to other ester prodrugs.

\section{Results and Discussion}

\subsection{Synthesis}

The reaction of LZDO with pivaloyl chloride in dichloromethane (DCM) solution under the catalytic action of pyridine, as conventional procedure, simultaneously resulted in compound M5 and D5 [28]. The remaining carboxylates were conveniently prepared in moderate yield through a one-step process by the reactions of LZDO with the corresponding carboxylic acids (capric acid, lauric acid, palmitic acid, and stearic acid) in DCM solution by the DMAP-catalyzed dicyclohexylcarbodiimide (DCC) method described in the literature [29]. The process is outlined in Scheme 1. Structures, melting points, yields and molecular weights of the ester products are summarized in Table 1. As shown, the 
melting points increased as the length of the side chain ascended in the set of linear aliphatic esters. The pivaloyl mono- and dual esters showed relatively higher melting points than corresponding linear esters. All esters synthesized here existed as solids.

Scheme 1. Synthesis of the prodrugs.<smiles>[R20]Cc1nc(C)c(CO[R2])nc1C</smiles>

Table 1. Structure; Yield; Melting Point; and Molecular Weight of prodrugs.

\begin{tabular}{cccccc}
\hline \multicolumn{5}{c}{} & \multicolumn{5}{c}{} \\
\hline Compound & $\mathbf{R}$ & $\mathbf{R}^{\prime}$ & Yield (\%) & M.p. $\left({ }^{\circ} \mathbf{C}\right)$ & MW (g/mol) \\
\hline M5 & $\mathrm{H}$ & Pivaloyl & 35 & $66-67$ & 252.15 \\
M10 & $\mathrm{H}$ & $n$-Decanoyl & 33 & $31-32$ & 322.23 \\
$\mathbf{M 1 2}$ & $\mathrm{H}$ & $n$-Dodecanoyl & 37 & $40-41$ & 350.26 \\
M16 & $\mathrm{H}$ & $n$-Hexadecanoyl & 30 & $60-62$ & 406.32 \\
M18 & $\mathrm{H}$ & $n$-Octadecanoyl & 35 & $65-66$ & 434.35 \\
D5 & Pivaloyl & Pivaloyl & 46 & $80-82$ & 336.20 \\
D10 & $n$-Decanoyl & $n$-Decanoyl & 45 & $46-47$ & 476.36 \\
D12 & $n$-Dodecanoyl & $n$-Dodecanoyl & 47 & $55-56$ & 532.42 \\
D16 & $n$-Hexadecanoyl & $n$-Hexadecanoyl & 48 & $74-75$ & 644.55 \\
D18 & $n$-Octadecanoyl & $n$-Octadecanoyl & 47 & $75-76$ & 700.61 \\
\hline
\end{tabular}

\subsection{Physiochemical Properties}

Appropriate physiochemical properties play critical roles in drug pharmacokinetics and development. The physiochemical properties including capacity factor, lipophilicity and solubility of these esters were examined and results listed in Table $2 . \log p$ values were obtained by means of computation and experiment. Obviously, the aqueous solubility of LZDO was good, but its lipophilicity was extremely low ( $\log p=-1.12$ ), which was the primary molecular property contributing to its short half-life. After esterification, the $\log p$ values for prodrugs of LZDO ranged from 1.33 for M5 to 3.77 for D12 respectively. During the determination of the partition coefficients, D16 and D18 both thoroughly partitioned into $n$-octanol, making the $\log p$ undetectable and, the calculated $\log p$ values impossible to obtain, demonstrating that their lipophilicity was too high to be a potent drug. The results also showed that there existed good linear correlation between the calculated $\log p$ values and the capacity factors, suggesting that $\mathrm{k}^{\prime}$ value could also be used to indicate lipophilicity more conveniently than the measure of $\log p$ values. Moreover as the carbon chain length gradually increased, the lipophilicity of the ester increased progressively, but the solubility decreased significantly. Even though the $\log p$ value of D5 was comparable to that of M10, the solubility for the former was more than threefold higher than that of M10, which was postulated to result from the branching of D5. The lipophilicity was in the order of LZDO $<$ M5 $<$ D5 $<$ M10 $<$ M12 $<$ M16 $<$ M18 $<$ D10 $<$ D12, and the solubility followed the order M12 $<$ M10 $<$ D5 $<$ M5 $<$ LZDO. 
Table 2. Capacity factor, Apparent Partition Coefficient and Aqueous Solubility $(n=3$; mean \pm SD).

\begin{tabular}{cccc}
\hline Compound & Capacity Factor & $\log \boldsymbol{P}^{\mathbf{a}}\left(\boldsymbol{C} \log \boldsymbol{P}^{b}\right)$ & Solubility $(\boldsymbol{\mu g} / \mathbf{m L})$ \\
\hline Liguzinediol & $0.100 \pm 0.004$ & $-1.12 \pm 0.11(-1.49)$ & $2.24 \times 10^{5} \pm 1.4 \times 10^{4}$ \\
M5 & $0.210 \pm 0.020$ & $1.33 \pm 0.10(0.60)$ & $8.0 \times 10^{3} \pm 3.5 \times 10^{2}$ \\
M10 & $0.400 \pm 0.015$ & $2.48 \pm 0.04(3.60)$ & $8.89 \pm 0.21$ \\
M12 & $0.514 \pm 0.012$ & $3.12 \pm 0.15(4.66)$ & $2.23 \pm 0.11$ \\
M16 & $0.834 \pm 0.012$ & $3.25 \pm 0.13(6.77)$ & n.d $^{c}$. \\
M18 & $1.055 \pm 0.061$ & $3.38 \pm 0.20(7.83)$ & n.d $^{c}$. \\
D5 & $0.364 \pm 0.039$ & $2.50 \pm 0.18(2.70)$ & $29.90 \pm 1.36$ \\
D10 & $1.068 \pm 0.057$ & $2.87 \pm 0.16(8.69)$ & n.d ${ }^{c}$. \\
D12 & $1.640 \pm 0.032$ & $3.77 \pm 0.21(10.80)$ & n.d ${ }^{c}$. \\
D16 & $3.911 \pm 0.042$ & n.d & n.d \\
D18 & $6.134 \pm 0.084$ & n.d & n.d \\
\hline
\end{tabular}

$\log P^{a}$ values were carried out in 1-octanol/phosphate buffer (7.4) at $25^{\circ} \mathrm{C} ; \log P^{b}$ values were calculated using ChemBioDraw Ultra 12.0 from CambridgeSoft; ${ }^{c}$ n.d: Not determined.

\subsection{Chemical Stabilities}

The chemical stabilities of the target products were analyzed by high-performance liquid chromatography (HPLC) and were calculated as the amount unchanged within $24 \mathrm{~h}$ in buffer solutions at $\mathrm{pH}$ 7.4. The results are reported in Table 3. The unchanged amount of all prodrugs was virtually above $98 \%$, indicating that all prodrugs were chemically stable.

Table 3. Stability of the prodrugs in buffered solutions, human serum and human liver microsomes $(n=3$; mean $\pm \mathrm{SD})$.

\begin{tabular}{|c|c|c|c|c|c|}
\hline Compound & 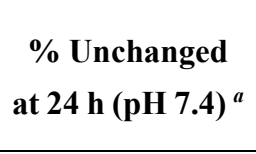 & $\begin{array}{c}\text { \% Max of LZDO } \\
\text { Released (80\% } \\
\text { Human Plasma) }^{b}\end{array}$ & $\begin{array}{c}\text { \% Max of LZDO } \\
\text { Released (Human } \\
\text { Liver Microsomes) }^{b}\end{array}$ & $\begin{array}{c}\text { t }_{1 / 2}(\mathbf{h}) \\
(80 \% H u m a n \\
{\text { Plasma })^{d}}^{d} \\
\end{array}$ & $\begin{array}{c}\mathbf{t}_{1 / 2}(\mathbf{h}) \\
\text { (Human Liver } \\
\text { Microsomes) }^{d}\end{array}$ \\
\hline M5 & $98.9 \pm 0.3$ & $79.2 \pm 2.2$ & $37.5 \pm 2.3$ & $2.6 \pm 0.1$ & $5.1 \pm 0.2$ \\
\hline M10 & $98.9 \pm 0.3$ & $85.4 \pm 3.1$ & $108.1 \pm 3.2$ & $2.3 \pm 0.2$ & $2.1 \pm 0.6$ \\
\hline M12 & $99.7 \pm 0.2$ & $64.2 \pm 2.3$ & $105.1 \pm 3.4$ & $2.6 \pm 0.5$ & $2.2 \pm 0.1$ \\
\hline M16 & $99.4 \pm 0.4$ & $44.5 \pm 2.2$ & $46.3 \pm 2.3$ & $3.3 \pm 0.6$ & $3.3 \pm 0.7$ \\
\hline M18 & $98.2 \pm 0.6$ & $15.6 \pm 1.6$ & $15.9 \pm 1.2$ & $9.6 \pm 1.1$ & $9.5 \pm 0.9$ \\
\hline D5 & $96.1 \pm 0.2$ & $28.6 \pm 2.4$ & $31.3 \pm 1.4$ & $3.4 \pm 0.4$ & $3.2 \pm 0.3$ \\
\hline D10 & $98.7 \pm 0.4$ & $23.4 \pm 1.2$ & $30.9 \pm 1.8$ & $4.2 \pm 0.4$ & $4.1 \pm 0.5$ \\
\hline D12 & $99.8 \pm 0.5$ & $8.7 \pm 1.7$ & $8.6 \pm 1.1$ & $7.9 \pm 1.0$ & $7.9 \pm 0.9$ \\
\hline D16 & stable $^{c}$ & n.d. ${ }^{e}$ & n.d. ${ }^{\mathrm{e}}$ & n.d. ${ }^{e}$ & n.d. ${ }^{\mathrm{e}}$ \\
\hline D18 & stable $^{\mathrm{c}}$ & n.d. ${ }^{\mathrm{e}}$ & n.d. ${ }^{\mathrm{e}}$ & n.d. ${ }^{\mathrm{e}}$ & n.d. ${ }^{e}$ \\
\hline
\end{tabular}

${ }^{a}$ Percent of compound remaining after $24 \mathrm{~h}$ in buffer solution; ${ }^{b}$ The maximum percentage of liguzinediol released at $6 \mathrm{~h}$ incubation; ${ }^{c}$ Compound was stable for the tested time period; ${ }^{d} \mathrm{t}_{1 / 2}$ values calculated from pseudo-first-order rate constant; ${ }^{e}$ n.d.: Not determined due to no degradation.

\subsection{In Vitro Metabolism}

For a rationally designed prodrug intended to prolong the half-life of the active moiety, the metabolic lability should be sufficient and continuous. Preliminary metabolic stability was assessed in human 
plasma and human liver microsomes The profile of disappearance of each prodrug followed a pseudo-first-order trend, and half-lives were calculated from the linear slopes of logarithmic plots of remaining prodrug over time [30]. Results are listed and compared in Table 3.

The metabolic rate in human plasma and liver microsomes was quite rapid relative to that observed in buffer solution, implying that the release of LZDO primarily depended on enzymatic hydrolysis. In the set of linear monoesters, the maximum percentage of LZDO released followed the series M10 > M12 > M16 > M18, in line with hypothesis that as the alkyl chain length extends, the metabolic stability of the ester is increased. Though D12 could be hydrolyzed, the maximum percentage of LZDO released was only $8.71 \%$ in plasma and $8.60 \%$ in liver microsomes. As expected, the introduction of two pivaloyl groups on the hydroxyl groups of LZDO to afford D5 weakened the production of LZDO relative to M10 with similar lipophilicity, suggesting that steric effects also influenced the metabolic stability of prodrugs. The peaks of M5, M10 and M12 were observed in the HPLC chromatograms during the hydrolysis of their corresponding dual compounds, suggesting that D5, D10 and D12 produced LZDO via the corresponding monoesters. Consequently, the dual esters with two ester bonds to cleave released less LZDO. Neither any amount of LZDO nor the respective monoesters of D16 and D18 was detected, showing that there was no bioconversion in both compounds, probably due to the solubility limitation and the high hydrophobicity hindering the encounter of esterases. Normally, there existed higher expression or activity of enzymes in liver microsomes than in plasma. Interestingly, M5 showed much higher metabolic rate in human plasma than in human liver microsomes, remarkably contrasting with other esters. Metabolic stability profiles of ester prodrugs involve a process of molecular recognition of esterase binding cavity, to which the molecular size, shape and lipophilicity of compounds were associated [31]. We therefore inferred that the steric hindrance of $\mathbf{M 5}$ reduced the susceptibility of the prodrug to hydrolytic enzymes in liver microsomes more than that in plasma. In the case of prodrugs M16, M18, D5, D10 and D12, the lack of a difference in maximum percentage of LZDO released in human plasma and human liver microsomes suggested that the molecular properties of these prodrugs primarily limited the liberation of LZDO but not the activities of the enzymes. Furthermore, the amount of LZDO released from M16, M18, D5, D10, D12, D16 and D18 in plasma and liver microsome was found to be poorly metabolized to permit the sufficient LZDO to be released. For M5, M10, and M12, the significantly differential maximum percentage of LZDO released in human plasma and human liver microsomes indicated that not only molecular properties but also activities of enzymes were involved in the liberation of LZDO. Moreover, the in vitro lability of M5, M10, and M12 was relatively sufficient to enter into in vivo pharmacokinetic screening.

\subsection{In Vivo Pharmacokinetics}

The detailed pharmacokinetic parameters are reported in Table 4 and the plasma concentration versus time profile is depicted in Figure 2. The pharmacokinetic profiles of LZDO after oral dosing of three ester prodrug forms (M5, M10, M12) and free LZDO demonstrated that as the lipophilicity escalated, the plasma $C_{\max }$ did not increase correspondingly, but rather decreased. The plasma $C_{\max }$ of LZDO was $33 \mu \mathrm{g} / \mathrm{mL}$, with M5 being $16 \mu \mathrm{g} / \mathrm{mL}$. For M10 and M12, the $C_{\max }$ values were too low, 12.07 and $9.07 \mu \mathrm{g} / \mathrm{mL}$ respectively. As expected, bioavailability more or less increased after the 
lipophilicity of LZDO $(\log p=-1.12)$ was improved. However, it was also clear that there existed a lipophilicity threshold above which lipophilicity exerted a negative effect on AUC values. Probably, it was due to insufficient solubility of the prodrugs influencing absorption. The AUC values were in the order of M5 $>$ M10 $>$ M12 $\approx$ LZDO. Furthermore, $T_{\max }$ values were $30 \mathrm{~min}$ with no significant difference between these three esters, a 15 min increase compared to LZDO dosed alone. $T_{1 / 2}$ values of LZDO after prodrug administration were all longer than that of free LZDO administration. $T_{1 / 2}$ of M5 was $7.8 \mathrm{~h}$, approximately an 8-fold increase compared to free oral dose of LZDO, a 4-fold increase relative to the diethylcarbonate prodrug of LZDO. For M10 and M12, $T_{1 / 2}$ was $9.99 \mathrm{~h}$ and $19.96 \mathrm{~h}$, respectively. Focusing on half-life, the $C_{\max }$ and AUC values of LZDO, M5 not only exhibited evidently prolonged elimination half-life, but also relatively good pharmacokinetic features. Typically, drug metabolism involvess phase I oxidation, followed by phase II conjugation. We therefore speculated that the slower release rate of LZDO from M5 in liver microsomes compared to plasma reduced the chance for phase II conjugation of LZDO in the liver.

Table 4. Pharmacokinetic parameters of LZDO after oral administration of free LZDO, M5, M10 and M12 (mean $\pm \mathrm{SD} ; n=6$ ).

\begin{tabular}{ccccc}
\hline Compound & Liguzinediol & M5 & M10 & M12 \\
\hline Dose & $25.2 \mathrm{mg} / \mathrm{kg}$ & $37.8 \mathrm{mg} / \mathrm{kg}$ & $48.3 \mathrm{mg} / \mathrm{kg}$ & $52.5 \mathrm{mg} / \mathrm{kg}$ \\
& $(0.15 \mathrm{mmol} / \mathrm{kg})$ & $(0.15 \mathrm{mmol} / \mathrm{kg})$ & $(0.15 \mathrm{mmol} / \mathrm{kg})$ & $(0.15 \mathrm{mmol} / \mathrm{kg})$ \\
\hline$T_{\max }(\mathrm{h})$ & 0.25 & 0.50 & 0.50 & 0.50 \\
$C_{\max }\left(\mu \mathrm{g} \cdot \mathrm{mL}^{-1}\right)$ & $33.00 \pm 1.59$ & $16.56 \pm 2.54$ & $12.07 \pm 1.69$ & $9.07 \pm 1.11$ \\
$t_{1 / 2}(\mathrm{~h})$ & $1.06 \pm 0.47$ & $7.81 \pm 5.43$ & $9.99 \pm 8.64$ & $19.96 \pm 9.96$ \\
$\mathrm{CL} / \mathrm{F}\left(\mathrm{L} \cdot \mathrm{h}^{-1} \cdot \mathrm{kg}^{-1}\right)$ & $0.59 \pm 0.04$ & $0.45 \pm 0.22$ & $0.57 \pm 0.24$ & $0.43 \pm 0.19$ \\
$\mathrm{AUC} C_{0-12 \mathrm{~h}}\left(\mu \mathrm{g} \cdot \mathrm{h} \cdot \mathrm{mL}^{-1}\right)$ & $40.43 \pm 2.26$ & $64.58 \pm 9.03$ & $57.78 \pm 3.31$ & $49.06 \pm 3.24$ \\
\hline
\end{tabular}

Figure 2. The plasma concentration versus time curves of LZDO after oral dosing of free LZDO, M5, M10 and M12 at equimolar doses of $0.15 \mathrm{mmol} / \mathrm{kg}$.

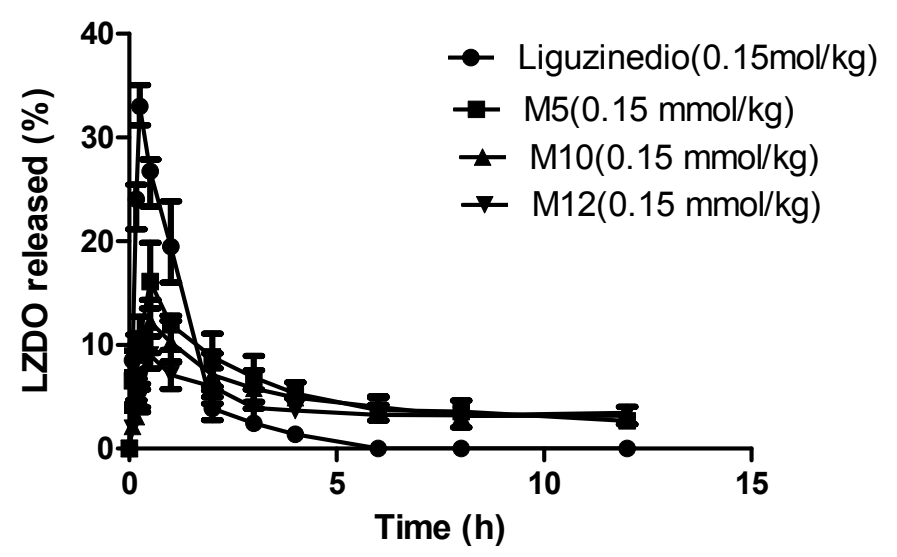

\section{Experimental Section}

\subsection{Materials and Solutions}

2,5-Dihydroxymethyl-3,6-dimethylpyrazine (LZDO, purity $=99.1 \%$ ) was prepared according to published procedures in our laboratory. Pivaloyl chloride, and pyridine were purchased from Nanjing 
Chemical Reagent Co., Ltd (Nanjing, China). Capric acid, lauric acid, palmitic acid, stearic acid, dicyclohexylcarbodiimide (DCC), 4-dimethylaminopyridine (DMAP), and $50 \mathrm{mM}$ phosphate buffer ( $\mathrm{pH}$ 7.4) were purchased from Sinopharm Chemical Reagent Co., Ltd (Nanjing, China). Human plasma was purchased from the Nanjing Red Cross Blood Center (Nanjing, China). Human liver microsomes and $\beta$-nicotinamide adenine dinucleotide 2'-phosphate reduced tetrasodium salt (NADPH) were purchased from Sigma-Aldrich (St. Louis, MO, USA). All solvents were of analytical grade. All other reagents were of HPLC grade. Double distilled water was used in all experiments.

\subsection{Synthesis}

The control of various reactions was monitored by thin layer chromatography (TLC). Melting points were determined on a Buchi B-540 melting point apparatus. The structures of all prodrug compounds were characterized by ${ }^{1} \mathrm{H}-\mathrm{NMR}$ (Bruker AV 300, Bruker BioSpin AG, Faellanden, Switzerland), ${ }^{13}$ C-NMR (Bruker AV 300), IR (Nicolet-100, Thermo Fisher Scientific Inc., Waltham, MA, USA), and mass spectra (Triple TOF 5600, AB SCIEX Corp., Framingham, MA, USA), and their purities were detected to be above $98 \%$ by HPLC (Waters 2695, Waters Corp., Milford, MA, USA).

\subsubsection{Preparation of 3,6-Dimethyl-5-hydroxymethyl-2-pivaloyloxymethylpyrazine (M5) and} 3,6-Dimethyl-2,5-dipivaloyloxymethylpyrazine (D5)

LZDO (1.68 g, $10 \mathrm{mmol}$ ) was dissolved in dichloromethane (20.0 mL, $26.5 \mathrm{~g}, 312 \mathrm{mmol}$ ), and the solution was placed on an ice bath. Then pivaloyl chloride $(5 \mathrm{~mL}, 4.925 \mathrm{~g}, 40 \mathrm{mmol})$ and distilled pyridine $(1.15 \mathrm{~mL}, 1.14 \mathrm{~g}, 14.35 \mathrm{mmol})$ were added slowly. After that, the reaction was kept for half an hour, then the ice bath was withdrawn and the mixture was stirred at ambient temperature for $12 \mathrm{~h}$. The reaction process was monitored by TLC using petroleum-ethyl acetate (3:1), with $R_{f}$ of M5 being 0.3 , and D5 0.7. The mixture was washed with saturated sodium bicarbonate solution $(3 \times 100 \mathrm{~mL})$, extracted with ethyl acetate $(4 \times 50 \mathrm{~mL})$, dried over anhydrous sodium sulphate, filtered, and the solvent was evaporated under vacuum. The purification of the two compounds was performed twice by column chromatography, using petroleum-ethyl acetate (3:1), to yield M5 and D5. The process is shown in Scheme 1.

3,6-Dimethyl-5-hydroxymethyl-2-pivaloyloxymethylpyrazine (M5). waxy white solid; mp 66-67 ${ }^{\circ} \mathrm{C}$; yield 35\%; ${ }^{1} \mathrm{H}-\mathrm{NMR}\left(300 \mathrm{MHz}, \mathrm{CDCl}_{3}\right) \delta 1.24(9 \mathrm{H}, \mathrm{s}), 2.44(3 \mathrm{H}, \mathrm{s}), 2.59(3 \mathrm{H}, \mathrm{s}), 4.24(1 \mathrm{H}, \mathrm{s}), 4.72$ $(2 \mathrm{H}, \mathrm{d}, \mathrm{J}=3.75 \mathrm{~Hz}), 5.23(2 \mathrm{H}, \mathrm{s}) ;{ }^{13} \mathrm{C}-\mathrm{NMR}\left(75 \mathrm{MHz}, \mathrm{CDCl}_{3}\right) \delta 19.26,20.32,27.20,38.91,60.97$, 64.95, 146.42, 147.16, 148.22, 150.15, 178.06; IR (KBr): $3263(v \mathrm{OH}), 2972\left(v^{\text {as }} \mathrm{CH}_{3}\right), 2872\left(v^{\mathrm{s}} \mathrm{CH}_{3}\right)$, 1728 (v C=O), $1429\left(\delta^{\text {as }} \mathrm{CH}_{3}\right), 1394,1367\left(\delta^{\mathrm{s}} \mathrm{CH}_{3}\right), 1151(v \mathrm{C}-\mathrm{O}) \mathrm{cm}^{-1}$; $\mathrm{ESI}(+)-\mathrm{MS}[\mathrm{M}+\mathrm{H}]^{+}$: calcd. for $\mathrm{C}_{13} \mathrm{H}_{20} \mathrm{~N}_{2} \mathrm{O}_{3} 253.1474$, found 253.1521 . HPLC analysis showed a purity of $98.12 \%$.

3,6-Dimethyl-2,5-dipivaloyloxymethylpyrazine (D5). Waxy white solid; mp $80-82{ }^{\circ} \mathrm{C}$; yield 46\%; ${ }^{1} \mathrm{H}-\mathrm{NMR}\left(300 \mathrm{MHz}, \mathrm{CDCl}_{3}\right) \delta 1.26(9 \mathrm{H} \times 2, \mathrm{~s}), 2.55(3 \mathrm{H} \times 2, \mathrm{~s}), 5.22(2 \mathrm{H} \times 2, \mathrm{~s}) ;{ }^{13} \mathrm{C}-\mathrm{NMR}(75 \mathrm{MHz}$, $\left.\mathrm{CDCl}_{3}\right) \delta 20.42,27.23,38.92,64.91,147.49,149.20,178.08$; IR $(\mathrm{KBr}): 2982\left(v^{\text {as }} \mathrm{CH}_{3}\right), 2873\left(8^{\mathrm{s}} \mathrm{CH}_{3}\right)$, 1730 (v C=O), $1421\left(v^{\text {as }} \mathrm{CH}_{3}\right), 1396,1366\left(\delta^{\mathrm{s}} \mathrm{CH}_{3}\right), 1148(v \mathrm{C}-\mathrm{O}) \mathrm{cm}^{-1}$; $\mathrm{ESI}(+)-\mathrm{MS}[\mathrm{M}+\mathrm{H}]^{+}$: calcd for $\mathrm{C}_{18} \mathrm{H}_{28} \mathrm{~N}_{2} \mathrm{O}_{4} 337.2049$, found 337.2118 . HPLC analysis showed a purity of $98.45 \%$. 


\subsubsection{General Preparation Procedure for Linear Chain Esters}

To a stirred solution of carboxylic acid $(10 \mathrm{mmol})$ in anhydrous $\mathrm{CH}_{2} \mathrm{Cl}_{2}(20.0 \mathrm{~mL}, 26.5 \mathrm{~g}, 312 \mathrm{mmol})$, DMAP (60 mg, $0.49 \mathrm{mmol})$ and LZDO (1.68 g, $10 \mathrm{mmol})$ were added. DCC (2.06 g, $10 \mathrm{mmol})$ was added to the reaction mixture at $0{ }^{\circ} \mathrm{C}$, which was then stirred for $30 \mathrm{~min}$ at $0{ }^{\circ} \mathrm{C}$ and the temperature was allowed to rise to room temperature, with stirring for another $8 \mathrm{~h}$. The precipitate was then filtered off to obtain filtrate which was successively washed twice with $0.5 \mathrm{~N} \mathrm{HCl}$ and with saturated $\mathrm{NaHCO}_{3}$ solution, dried over anhydrous $\mathrm{MgSO}_{4}$. The solvent was removed by evaporation and immediately purified by silica gel column chromatography, using petroleum-ethyl acetate (3:1) as eluent, to yield corresponding mono-ester and dual-ester from one reaction. The carboxylic acids used were capric acid, lauric acid, hexadecanoic acid and, stearic acid, respectively. The procedure is shown in Scheme 1.

2-Decanoyloxymethyl-3,6-dimethyl-5-hydroxymethylpyrazine (M10). Waxy white solid; mp 31-32 ${ }^{\circ} \mathrm{C}$; yield 33\%; ${ }^{1} \mathrm{H}-\mathrm{NMR}\left(300 \mathrm{MHz}, \mathrm{CDCl}_{3}\right) \delta 0.89(3 \mathrm{H}, \mathrm{t}, J=6.39 \mathrm{~Hz}), 1.27-1.29(12 \mathrm{H}, \mathrm{m}), 1.64(2 \mathrm{H}, \mathrm{m})$, $2.39(2 \mathrm{H}, \mathrm{t}, J=7.41 \mathrm{~Hz}), 2.47(3 \mathrm{H}, \mathrm{s}), 2.60(3 \mathrm{H}, \mathrm{s}), 4.24(1 \mathrm{H}, \mathrm{t}, J=4.62 \mathrm{~Hz}), 4.72(2 \mathrm{H}, \mathrm{d}, J=4.5 \mathrm{~Hz})$, $5.25(2 \mathrm{H}, \mathrm{s}) ;{ }^{13} \mathrm{C}-\mathrm{NMR}\left(75 \mathrm{MHz}, \mathrm{CDCl}_{3}\right) \delta 14.07,19.29,20.37,22.63,24.94,29.11,29.22,29.38$, $31.83,33.95,34.08,60.97,64.58,146.21,147.35,148.17,150.31,173.42$; IR (KBr): $3445(v \mathrm{vH})$, $2926\left(v^{\text {as }} \mathrm{CH}_{2}\right), 2854\left(v^{\mathrm{s}} \mathrm{CH}_{2}\right), 1741$ (v $\left.\mathrm{C}=\mathrm{O}\right), 1425\left(\delta^{\mathrm{as}} \mathrm{CH}_{3}\right), 1377\left(\delta^{\mathrm{s}} \mathrm{CH}_{3}\right), 1157$ (v C-O) cm ${ }^{-1}$; $\mathrm{ESI}(+)-\mathrm{MS}[\mathrm{M}+\mathrm{H}]^{+}$: calcd. for $\mathrm{C}_{18} \mathrm{H}_{30} \mathrm{~N}_{2} \mathrm{O}_{3}$ 323.2256, found 323.2305. HPLC analysis showed a purity of $98.32 \%$.

2,5-Didecanoyloxymethyl-3,6-dimethylpyrazine (D10). Waxy white solid; mp 46-47 ${ }^{\circ} \mathrm{C}$; yield 45\%; ${ }^{1} \mathrm{H}-\mathrm{NMR}\left(300 \mathrm{MHz}, \mathrm{CDCl}_{3}\right) \delta 0.89(3 \mathrm{H} \times 2, \mathrm{t}, J=6.36 \mathrm{~Hz}), 1.27-1.30(12 \mathrm{H} \times 2, \mathrm{~m}), 1.65(2 \mathrm{H} \times 2, \mathrm{~m})$, $2.39(2 \mathrm{H} \times 2, \mathrm{t}, J=7.44 \mathrm{~Hz}), 2.56(3 \mathrm{H} \times 2, \mathrm{~s}), 5.23(2 \mathrm{H} \times 2, \mathrm{~s}) ;{ }^{13} \mathrm{C}-\mathrm{NMR}\left(75 \mathrm{MHz}, \mathrm{CDCl}_{3}\right) \delta 14.07$, 20.51, 22.63, 24.95, 29.12, 29.22, 29.38, 31.83, 32.78, 34.08, 64.58, 147.47, 149.35, 173.39; IR (KBr): $2925\left(v^{\text {as }} \mathrm{CH}_{2}\right), 2851\left(v^{\mathrm{s}} \mathrm{CH}_{2}\right), 1741(v \mathrm{C}=\mathrm{O}), 1428\left(\delta^{\mathrm{as}} \mathrm{CH}_{3}\right), 1385\left(\delta^{\mathrm{s}} \mathrm{CH}_{3}\right), 1151(v \mathrm{C}-\mathrm{O}), 721\left(\rho \mathrm{CH}_{2}\right)$ $\mathrm{cm}^{-1}$; $\mathrm{ESI}(+)-\mathrm{MS}[\mathrm{M}+\mathrm{H}]+$ : calcd. for $\mathrm{C}_{28} \mathrm{H}_{48} \mathrm{~N}_{2} \mathrm{O}_{4} 477.3614$, found 477.3675. HPLC analysis showed a purity of $98.56 \%$.

3,6-Dimethyl-2-dodecanoyloxymethyl-5-hydroxymethylpyrazine (M12). Waxy white solid; $\mathrm{mp} 40-41{ }^{\circ} \mathrm{C}$; yield 37\%; ${ }^{1} \mathrm{H}-\mathrm{NMR}\left(300 \mathrm{MHz}, \mathrm{CDCl}_{3}\right) \delta 0.88(3 \mathrm{H}, \mathrm{t}, J=6.81 \mathrm{~Hz}), 1.21-1.40(16 \mathrm{H}, \mathrm{m}), 1.63(2 \mathrm{H}, \mathrm{m})$, $2.35(2 \mathrm{H}, \mathrm{t}, J=7.35 \mathrm{~Hz}), 2.44(3 \mathrm{H}, \mathrm{s}), 2.59(3 \mathrm{H}, \mathrm{s}), 4.25(1 \mathrm{H}, \mathrm{t}, J=4.65 \mathrm{~Hz}), 4.75(2 \mathrm{H}, \mathrm{d}, J=4.5 \mathrm{~Hz})$, $5.20(2 \mathrm{H}, \mathrm{s}) ;{ }^{13} \mathrm{C}-\mathrm{NMR}\left(75 \mathrm{MHz}, \mathrm{CDCl}_{3}\right) \delta 14.09,19.29,20.37,22.67,24.95,29.12,29.23,29.34$, 29.44, 29.57, 29.67, 31.91, 34.09, 60.97, 64.58, 146.21, 147.34, 148.17, 150.31, 173.42; IR (KBr): $3356(v \mathrm{vH}), 2918\left(v^{\text {as }} \mathrm{CH}_{2}\right), 2849\left(v^{\mathrm{s}} \mathrm{CH}_{2}\right), 1737(v \mathrm{C}=\mathrm{O}), 1424\left(\delta^{\mathrm{as}} \mathrm{CH}_{3}\right), 1379\left(\delta^{\mathrm{s}} \mathrm{CH}_{3}\right), 1162$ (v C-O), $719\left(\rho \mathrm{CH}_{2}\right) \mathrm{cm}^{-1}$; $\mathrm{ESI}(+)-\mathrm{MS}[\mathrm{M}+\mathrm{H}]^{+}$: calcd. for $\mathrm{C}_{20} \mathrm{H}_{34} \mathrm{~N}_{2} \mathrm{O}_{3}$ 351.2569, found 351.2618. HPLC analysis showed a purity of $98.68 \%$.

2,5-Didodecanoyloxymethyl-3,6-dimethylpyrazine (D12). Waxy white solid; mp 55-56 ${ }^{\circ} \mathrm{C}$; yield 47\%; ${ }^{1} \mathrm{H}-\mathrm{NMR}\left(300 \mathrm{MHz}, \mathrm{CDCl}_{3}\right) \delta 0.89(3 \mathrm{H} \times 2, \mathrm{t}, J=6.93 \mathrm{~Hz}), 1.25-1.40(16 \mathrm{H} \times 2, \mathrm{~m}), 1.64(2 \mathrm{H} \times 2, \mathrm{~m})$, $2.39(2 \mathrm{H} \times 2, \mathrm{t}, J=7.59 \mathrm{~Hz}), 2.56(3 \mathrm{H} \times 2, \mathrm{~s}), 5.22(2 \mathrm{H} \times 2, \mathrm{~s}) ;{ }^{13} \mathrm{C}-\mathrm{NMR}\left(75 \mathrm{MHz}, \mathrm{CDCl}_{3}\right) \delta 14.07$, 20.51, 22.66, 24.95, 29.12, 29.23, 29.30, 29.42, 29.57, 31.88, 34.07, 64.58, 147.46, 149.34, 173.37; IR (KBr): $2915\left(v^{\text {as }} \mathrm{CH}_{2}\right), 2849\left(v^{\mathrm{s}} \mathrm{CH}_{2}\right), 1738(v \mathrm{C}=\mathrm{O}), 1416\left(\delta^{\text {as }} \mathrm{CH}_{3}\right), 1381\left(\delta^{\mathrm{s}} \mathrm{CH}_{3}\right), 1160$ (v C-O$), 719$ 
$\left(\rho \mathrm{CH}_{2}\right) \mathrm{cm}^{-1}$; $\mathrm{ESI}(+)-\mathrm{MS}[\mathrm{M}+\mathrm{H}]^{+}$: calcd. for $\mathrm{C}_{32} \mathrm{H}_{56} \mathrm{~N}_{2} \mathrm{O}_{4}$ 533.4240, found 533.4299. HPLC analysis showed a purity of $98.27 \%$.

3,6-Dimethyl-2-hexadecanoyloxymethyl-5-hydroxymethylpyrazine (M16). Waxy white solid; mp 60-62 ${ }^{\circ} \mathrm{C}$; yield 30\%; ${ }^{1} \mathrm{H}-\mathrm{NMR}\left(300 \mathrm{MHz}, \mathrm{CDCl}_{3}\right) \delta 0.89(3 \mathrm{H}, \mathrm{t}, J=6.93 \mathrm{~Hz}), 1.21-1.40(24 \mathrm{H}, \mathrm{m})$, $1.66(2 \mathrm{H}, \mathrm{m}), 2.39(2 \mathrm{H}, \mathrm{t}, J=7.56 \mathrm{~Hz}), 2.45(3 \mathrm{H}, \mathrm{s}), 2.60(3 \mathrm{H}, \mathrm{s}), 4.24(1 \mathrm{H}, \mathrm{t}, J=4.65 \mathrm{~Hz}), 4.72(2 \mathrm{H}, \mathrm{d}$, $J=4.62 \mathrm{~Hz}), 5.25(2 \mathrm{H}, \mathrm{s}) ;{ }^{13} \mathrm{C}-\mathrm{NMR}\left(75 \mathrm{MHz}, \mathrm{CDCl}_{3}\right) \delta 14.07,19.29,20.35,21.40,21.52,22.65$, 24.87, 24.93, 29.11, 29.21, 29.29, 29.41, 29.56, 31.87, 34.02, 34.07, 60.99, 64.56, 146.21, 147.36, 148.16, 150.33, 173.39; IR ( $\mathrm{KBr}): 3361(\mathrm{v} \mathrm{OH}), 2917\left(v^{\text {as }} \mathrm{CH}_{2}\right), 2849\left(v^{\mathrm{s}} \mathrm{CH}_{2}\right), 1737(\mathrm{v} \mathrm{C}=\mathrm{O}), 1425$ $\left(\delta^{\text {as }} \mathrm{CH}_{3}\right), 1380\left(\delta^{\mathrm{s}} \mathrm{CH}_{3}\right), 1162$ (v C-O), $719\left(\rho \mathrm{CH}_{2}\right) \mathrm{cm}^{-1}$; $\mathrm{ESI}(+)-\mathrm{MS}[\mathrm{M}+\mathrm{H}]^{+}$: calcd. for $\mathrm{C}_{24} \mathrm{H}_{42} \mathrm{~N}_{2} \mathrm{O}_{3}$ 407.3195, found 407.3231. HPLC analysis showed a purity of $98.76 \%$.

2,5-Dihexadecanoyloxymethyl-3,6-dimethylpyrazine (D16). Waxy white solid; mp $74-75{ }^{\circ} \mathrm{C}$; yield $48 \%$; ${ }^{1} \mathrm{H}-\mathrm{NMR}\left(300 \mathrm{MHz}, \mathrm{CDCl}_{3}\right) \delta 0.90(3 \mathrm{H} \times 2, \mathrm{t}, J=6.93 \mathrm{~Hz}), 1.25-1.40(24 \mathrm{H} \times 2, \mathrm{~m}), 1.67(2 \mathrm{H} \times 2, \mathrm{~m})$, $2.40(2 \mathrm{H} \times 2, \mathrm{t}, J=7.56 \mathrm{~Hz}), 2.57(3 \mathrm{H} \times 2, \mathrm{~s}), 5.23(2 \mathrm{H} \times 2, \mathrm{~s}) ;{ }^{13} \mathrm{C}-\mathrm{NMR}\left(75 \mathrm{MHz}, \mathrm{CDCl}_{3}\right) \delta 14.11$, $17.67,20.53,22.68,24.96,29.14,29.25,29.35,29.45,29.59,29.68,31.92,34.09,64.59,147.47$, 149.15, 179.37; IR (KBr): $2916\left(v^{\text {as }} \mathrm{CH}_{2}\right), 2849\left(v^{\mathrm{s}} \mathrm{CH}_{2}\right), 1738(v \mathrm{C}=\mathrm{O}), 1420\left(\delta^{\text {as }} \mathrm{CH}_{3}\right), 1381$ ( $\left.\delta^{\mathrm{s}} \mathrm{CH}_{3}\right), 1161$ (v C-O), $719\left(\rho \mathrm{CH}_{2}\right) \mathrm{cm}^{-1}$; $\mathrm{ESI}(+)-\mathrm{MS}[\mathrm{M}+\mathrm{H}]^{+}$: calcd. for $\mathrm{C}_{40} \mathrm{H}_{72} \mathrm{~N}_{2} \mathrm{O}_{4} 645.5492$, found 645.5572 . HPLC analysis showed a purity of $98.17 \%$.

3,6-Dimethyl-5-hydroxy-2-octadecanoyloxymethylpyrazine (M18). Waxy white solid; mp 65-66 ${ }^{\circ} \mathrm{C}$; yield 35\%; ${ }^{1} \mathrm{H}-\mathrm{NMR}\left(300 \mathrm{MHz}, \mathrm{CDCl}_{3}\right) \delta 0.89(3 \mathrm{H}, \mathrm{t}, J=6.99 \mathrm{~Hz}), 1.21-1.40(28 \mathrm{H}, \mathrm{m}), 1.66(2 \mathrm{H}, \mathrm{m})$, $2.39(2 \mathrm{H}, \mathrm{t}, J=7.56 \mathrm{~Hz}), 2.45(3 \mathrm{H}, \mathrm{s}), 2.60(3 \mathrm{H}, \mathrm{s}), 4.25(1 \mathrm{H}, \mathrm{t}, J=4.56 \mathrm{~Hz}), 4.72(2 \mathrm{H}, \mathrm{d}, J=4.56 \mathrm{~Hz})$, $5.25(2 \mathrm{H}, \mathrm{s}) ;{ }^{13} \mathrm{C}-\mathrm{NMR}\left(75 \mathrm{MHz}, \mathrm{CDCl}_{3}\right) \delta 14.10,19.29,20.38,22.68,24.95,29.13,29.24,29.34$, 29.44, 29.58, 29.68, 31.91, 34.09, 60.97, 64.58, 146.21, 147.34, 148.17, 150.31, 173.43; IR (KBr): 3411(v OH), $2917\left(v^{\text {as }} \mathrm{CH}_{2}\right), 2849\left(v^{\mathrm{s}} \mathrm{CH}_{2}\right), 1737(v \mathrm{C}=\mathrm{O}), 1425\left(\delta^{\mathrm{as}} \mathrm{CH}_{3}\right), 1380\left(\delta^{\mathrm{s}} \mathrm{CH}_{3}\right), 1163$ (v C-O), $719\left(\rho \mathrm{CH}_{2}\right) \mathrm{cm}^{-1}$; $\mathrm{ESI}(+)-\mathrm{MS}[\mathrm{M}+\mathrm{H}]^{+}$: calcd. for $\mathrm{C}_{26} \mathrm{H}_{46} \mathrm{~N}_{2} \mathrm{O}_{3} 435.3508$, found 435.3542 . HPLC analysis showed a purity of $98.69 \%$.

3,6-Dimethyl-2,5-dioctadecanoyloxymethylpyrazine (D18). Waxy white solid; $\mathrm{mp} 75-76{ }^{\circ} \mathrm{C}$; yield $47 \%$; ${ }^{1} \mathrm{H}-\mathrm{NMR}\left(300 \mathrm{MHz}, \mathrm{CDCl}_{3}\right) \delta 0.90(3 \mathrm{H} \times 2, \mathrm{t}, J=6.93 \mathrm{~Hz}), 1.25-1.40(28 \mathrm{H} \times 2, \mathrm{~m}), 1.67(2 \mathrm{H} \times 2$, $\mathrm{m}), 2.38(2 \mathrm{H} \times 2, \mathrm{t}, J=7.56 \mathrm{~Hz}), 2.58(3 \mathrm{H} \times 2, \mathrm{~s}), 5.25(2 \mathrm{H} \times 2, \mathrm{~s}) ;{ }^{13} \mathrm{C}-\mathrm{NMR}\left(75 \mathrm{MHz}, \mathrm{CDCl}_{3}\right) \delta$ $14.11,17.67,20.53,22.68,24.96,29.14,29.25,29.35,29.45,29.59,29.68,31.92,34.09,64.61,147.47$, 149.15, 179.37; IR (KBr): $2917\left(v^{\text {as }} \mathrm{CH}_{2}\right), 2848\left(v^{\mathrm{s}} \mathrm{CH}_{2}\right), 1738(v \mathrm{C}=\mathrm{O}), 1425\left(\delta^{\text {as }} \mathrm{CH}_{3}\right), 1162$ (v C-O), $719\left(\rho \mathrm{CH}_{2}\right) \mathrm{cm}^{-1}$; $\mathrm{ESI}(+)-\mathrm{MS}[\mathrm{M}+\mathrm{H}]^{+}$: calcd. for $\mathrm{C}_{44} \mathrm{H}_{80} \mathrm{~N}_{2} \mathrm{O}_{4}$ 701.6118, found 701.6191 . HPLC analysis showed a purity of $98.38 \%$.

\subsection{Physicochemical Properties}

\subsubsection{Determination of Lipophilic Index}

According to the method described in the literature [32], the capacity factor $\left(\mathrm{k}^{\prime}\right)$ of the prodrugs was determined using high-performance liquid chromatography (HPLC). Retention times of each prodrug and LZDO were measured and $\mathrm{k}^{\prime}$ values were calculated from the following equation: 


$$
\mathrm{k}^{\prime}=\left(\mathrm{t}^{\prime}-\mathrm{t}_{0}\right) / \mathrm{t}_{0}
$$

where $t_{0}$ is the retention time of the uracil and $t^{\prime}$ is the retention time of each compound. All experiments were conducted in triplicate.

\subsubsection{Partition Coefficient Determination}

Partitioning studies were performed with $n$-octanol and $50 \mathrm{mM}$ phosphate buffer solution (pH 7.4) following standard procedures described in the literature [33]. All experiments were conducted in triplicate, and the determination of LZDO was also carried out as a reference. Meanwhile, ChemBioDraw Ultra 12.0 was used to determine the calculated $\log p$ values as reference to the observed values.

\subsubsection{Solubility Studies}

An excess of each prodrug was added to $5 \mathrm{~mL}$ of $50 \mathrm{mM}$ phosphate buffer solution (pH 7.4), and shaken at $25{ }^{\circ} \mathrm{C}$ in a water bath to establish equilibration for $24 \mathrm{~h}$. After the equilibration, the samples were filtered through a membrane filter $(0.45 \mu \mathrm{m})$ and analyzed by HPLC. All experiments were conducted in triplicate [34].

\subsection{Hydrolysis in Phosphate Buffer (pH 7.4)}

Methanolic stock solutions of each compound were added to $10 \mathrm{~mL}$ of $50 \mathrm{mM}$ phosphate buffer solution (pH 7.4). The resulting solution was placed in a constant shaker bath set at $37{ }^{\circ} \mathrm{C}$ and after $24 \mathrm{~h}$, a $10 \mu \mathrm{L}$ aliquot of reaction solution was taken and analyzed by HPLC [35]. All experiments were performed in triplicate.

\subsection{Hydrolysis in Human Serum}

A prodrug $(100 \mu \mathrm{L}$, initial concentrations were $4.20-9.85 \mathrm{mM})$ in methanol was added to human plasma $(1000 \mu \mathrm{L})$ diluted to $80 \%$ with $50 \mathrm{mM}$ phosphate buffer solution (pH 7.4) and was placed in a constant shaker bath set. The resulting solution was subsequently incubated at $37{ }^{\circ} \mathrm{C}$ and at appropriate time intervals methanol $(1 \mathrm{~mL})$ containing caffeine as internal standard was added in order to deproteinize the serum. The sample was vortexed for $3 \mathrm{~min}$, and then centrifuged for $5 \mathrm{~min}$ at 5000 g. $900 \mu \mathrm{L}$ of clear supernatant was withdrawn and evaporated to remove the solvent. Before analysis by RP-HPLC, the samples were dissolved in methanol $(200 \mu \mathrm{L})$, vortexed again for 5 min, and then centrifuged for $5 \mathrm{~min}$ at 12,000 $\mathrm{g}$. All experiments were performed at least in triplicate.

\subsection{Metabolism Studies in Human Liver Microsomes}

To the human liver microsomes which were dissolved in $50 \mathrm{mM}$ phosphate buffer solution ( $\mathrm{pH} 7.4$ ) to a concentration of $1 \mathrm{mg} / \mathrm{mL}$, a prodrug $(100 \mu \mathrm{L}$, initial concentrations were $4.20-9.85 \mathrm{mM})$ in methanol and NADPH $(100 \mu \mathrm{L}, 1 \mathrm{mM})$ also in $50 \mathrm{mM}$ phosphate buffer solution $(\mathrm{pH} 7.4)$ were successively added to initiate the incubation. The solution was then incubated at $37{ }^{\circ} \mathrm{C}$ and the subsequent procedures of sample preparations were similar to those in Section 3.5. All experiments were performed at least in triplicate. 


\subsection{In Vivo Pharmacokinetic Studies}

\subsubsection{Rat Experiment}

The experiments were performed in the certified Laboratory Animal Center (Nanjing University of Chinese Medicine, Nanjing, China); the license number of the rats was SCXK (Zhejiang) 2014-0001. The studies were conducted according to the Guide for the Care and Use of Laboratory Animals [36]. Male Sprague-Dawley rats (Hangzhou, China) weighing 220-250 g were fasted for $12 \mathrm{~h}$ prior to experiments with free access to water. Animals were randomly assigned to four groups and each group received one substance (LZDO, M5, M10, and M12) suspended in 0.5\% CMC-Na solution [37]. The dosages of prodrug M5 $(0.15 \mathrm{mmol} / \mathrm{kg}), \mathbf{M 1 0}(0.15 \mathrm{mmol} / \mathrm{kg})$, and $\mathbf{M 1 2}(0.15 \mathrm{mmol} / \mathrm{kg})$ were $37.8 \mathrm{mg} / \mathrm{kg}, 48.3 \mathrm{mg} / \mathrm{kg}, 52.5 \mathrm{mg} / \mathrm{kg}$, respectively. All dosages of prodrug were equivalent to $25.5 \mathrm{mg} / \mathrm{kg}$ of LZDO $(0.15 \mathrm{mmol} / \mathrm{kg})$. After oral administration of all substances by oral gavage, blood samples of $0.3 \mathrm{~mL}$ were collected from the ophthalmic venous plexus and put into heparinized Eppendorf tubes at $0.083,0.167,0.25,0.5,1,2,3,4,6,8$ and $12 \mathrm{~h}$ [38]. Blood samples from each animal were immediately centrifuged for $10 \mathrm{~min}$ at $5000 \mathrm{~g}$ and $100 \mu \mathrm{L}$ of plasma was then removed and stored at $-80{ }^{\circ} \mathrm{C}$ until determination by HPLC.

\subsubsection{Sample Treatment}

Before analysis, blood samples were taken and thawed. Ten $\mu \mathrm{L}$ of $0.1 \mathrm{mg} / \mathrm{mL}$ caffeine as internal standard was added to blood sample. The following procedures such as precipitation, centrifugation and reconstitution were the same as sample preparations in Section 3.5.

\subsubsection{Pharmacokinetics and Statistical Analysis}

$C_{\max }$ and $T_{\max }$ values were directly obtained from the plasma-concentration time curves and the area under the plasma-concentration time curves $\left(\mathrm{AUC}_{0 \rightarrow \mathrm{t}}\right)$ were determined by the trapezoidal method. The other pharmacokinetic parameters were calculated on the basis of non-compartmental analysis of the concentration-time profile using pharmacokinetic software package DAS.2.0. The results were expressed as mean $\pm \mathrm{SD}$.

\subsection{Analytical Procedures}

Separation and quantitation of the releasing LZDO and the prodrugs were carried out using a HPLC procedure. The HPLC system was equipped with a Waters 2695 gradient pump, a Waters 2487 UV detector at $278 \mathrm{~nm}$, and an Empower 2 data station. The analytical column for in vitro samples was a Boston Green ODS-AQ column $(4.6 \mathrm{~mm} \times 50 \mathrm{~mm}, 5 \mu \mathrm{m})$ and the injection volume was $10 \mu \mathrm{L}$. Gradient elution methods were performed with a flow rate at $1.0 \mathrm{~mL} / \mathrm{min}$ on Boston Green ODS-AQ column maintained at $30{ }^{\circ} \mathrm{C}$. The percentage of mobile phase consisting of methanol and water was varied to elute analytes (see Supplementary Material for details of the HPLC elution). The methods provided rapid analysis for quantifying LZDO, prodrug and internal standard simultaneously. When qualifying the releasing amount of LZDO, separate standard curves under specific analytic condition were prepared by spiking a known amount of LZDO and internal standard in blank matrix. 
Disappearance of each prodrug from in vitro samples was analyzed by taking the ratio of peak areas detected at sampling time to that at initial time. As for in vivo pharmacokinetic analysis, determinations only referred to LZDO and an Ultimate XB-C18 column $(3.0 \mathrm{~mm} \times 50 \mathrm{~mm}, 3 \mu \mathrm{m})$ with an injection volume of $2 \mu \mathrm{L}$ was used. The flow rate on Ultimate XB-C18 column was $0.4 \mathrm{~mL} / \mathrm{min}$ with a column temperature of $30^{\circ} \mathrm{C}$. The mobile phase consisted of methanol (A) and water (B). The initial mobile phase composition was 4\% A/96\% B and maintained for 8 min. After that the mobile phase composition was changed to $80 \% \mathrm{~A} / 20 \% \mathrm{~B}$ over $4 \mathrm{~min}$ and held at that ratio for an additional $4 \mathrm{~min}$. The mobile phase was returned to initial composition over $1 \mathrm{~min}$ and re-equilibrated for 3 min. For in vivo analytical samples, a separate standard curve was prepared using blank rat plasma and ranged from 0.39 to $50 \mu \mathrm{g} / \mathrm{mL}$.

\section{Conclusions}

For LZDO, the hurdle of a desirable pharmacokinetic profile for the oral chronic administration is low lipophilicity resulting in its rapid elimination. Nevertheless, in vivo studies also demonstrated that too poor solubility of M10 and M12 also impeded satisfactory pharmacokinetic characteristics, presenting very low $C_{\max }$ values. This study in principle observed that the LZDO ester with carbon atom linear chain lengths above 10 was less feasible to release LZDO sufficiently relative to M5 while it increased metabolic stability and extended the retention of LZDO. Pivaloyl moieties are often applied in prodrug strategies to accomplish different purposes. Herein, the application of conjugating a pivaloyl moiety with LZDO to release LZDO slowly was also successful. Further, a molecular weight of $254 \mathrm{~g} / \mathrm{mol}$, adequate lipophilicity with $\log p$ of 1.33 , and good solubility $(8 \mathrm{mg} / \mathrm{mL})$ of the monopivaloyl ester jointly contributed to a favorable pharmacokinetic profile and extended half-time, according to "Lipinski's rule of five" [39]. During synthesis, we also found that monoester prodrugs of LZDO containing eight carbon atom linear chain lengths existed as oils (data not shown). Thus, a monoester prodrug of LZDO with a carbon atom chain length of less than 10 will be considered to be designed in the form of a branched chain; of which we would like to further explore as a promising LZDO ester prodrug candidate in the future.

In summary, the length and structure of the alkyl side chain in prodrug molecules determined the physiochemical properties, in vitro metabolic stability and the in vivo pharmacokinetics of LZDO. In other words, introducing "prodrug design" into drug design of new chemical entities in the earliest stages of research and development might help LZDO to overcome the deficiency of being unable to show an adequate half-life in its basic form for oral chronic medication. In this work, a monopivaloyl ester presented the optimal pharmacokinetic feature with intriguing physiochemical properties, and was selected for further development.

\section{Acknowledgments}

This work was financially supported by the National Natural Science Foundation of China (81072542), the Specialized Research Fund for the Doctoral Program of Higher Education of China (20123237110010), the Natural Science Foundation of Jiangsu Province (BK2011077), and a Project Funded by the Priority Academic Program Development of Jiangsu Higher Education Institutions (PAPD). 


\section{Author Contributions}

Wei Li, Hong-Mei Wen and Jing Zhang designed research; Jing Zhang, Hao-Hao Zhu, Dong Cheng, Kun-Di Yang and Yu-Qing Chen performed research and analyzed the data; Jing Zhang, Wei Li and Tian-Lin Wang wrote the paper. All authors read and approved the final manuscript.

\section{Conflicts of Interest}

The authors declare no conflict of interest.

\section{References}

1. Cowie, M.R.; Mosterd, A.; Wood, D.A.; Deckers, J.W.; Poole-Wilson, P.A.; Sutton, G.C.; Grobbeef, D.E. The epidemiology of heart failure. Eur. Heart J. 1997, 18, 208-225.

2. Toller, W.G.; Stranz, C. Levosimendan, a new inotropic and vasodilator agent. Anesthesiology 2006, 104, 556-569.

3. Cohn, J.N.; Goldstein, S.O.; Greenberg, B.H.; Lorell, B.H.; Bourge, R.C.; Jaski, B.E.; Gottlieb, S.O.; Demets, D.L.; White, B.G. A dose-dependent increase in mortality with vesnarinone among patients with severe heart failure. New. Engl. J. Med. 1998, 339, 1810-1816.

4. O’Connor, C.M.; Gattis, W.A.; Uretsky, B.F.; Adams, K.F.; McNulty, S.E.; Grossman, S.H.; McKenna, W.J.; Zannad, F.; Swedberg, K.; Gheorghiade, M.; et al. Continuous intravenous dobutamine is associated with an increased risk of death in patients with advanced heart failure: Insights from the Flolan International Randomized Survival Trial (FIRST). Am. Heart J. 1999, 138, $78-86$.

5. Cuffe, M.S.; Califf, R.M.; Adams, K.F., Jr.; Benza, R.; Bourge, R.; Colucci, W.S.; Massie, B.M.; O'Connor, C.M.; Pina, I.; Quigg, R.; et al. Short-term intravenous milrinone for acute exacerbation of chronic heart failure: A randomized controlled trial. JAMA 2002, 287, 1541-1547.

6. Gjesdal, K.; Feyzi, J.; Olsson, S.B. Digitalis: A dangerous drug in atrial fibrillation? An analysis of the SPORTIF III and V data. Heart 2008, 94, 191-196.

7. Chen, L.; Xu, Y.; Li, W.; Wu, H.; Luo, Z.K.; Li, X.H.; Huang, F.F.; Young, C.; Liu, Z.; Zhou, S.Y. The novel compound LZDO exerts positive inotropic effects in isolated rat heart via sarcoplasmic reticulum $\mathrm{Ca}^{2+}$ ATPase-dependent mechanism. Life Sci. 2012, 91, 402-408.

8. Larissa, L.; Elie, R.C.; Lahouaria, H.; Anne-Marie, L.; Roger, J.H. Sarcoplasmic reticulum Ca ${ }^{2+}$ ATPase as a therapeutic target for heart failure. Expert Opin. Biol. Ther. 2010, 10, 29-41.

9. Liu, Z.; Zhou, S.Y.; Li, W.; Wen, H.M.; Bian, H.M.; Chen, L. Liguzinediol induced positive inotropic effect in normal isolated rat hearts. Chin. J. New Drugs Clin. Remedies 2009, 28, 293-296.

10. Liu, Z.; Bian, H.M.; Chen, L.; Li, W.; Wen, H.M. Effect of liguzinediol on cardiac hemodynamics in healty rats. Chin. Pharm. J. 2009, 44, 1155-1158.

11. Zhang, D.N.; Guo, Y.; Li, Z.Q.; Li, W.; Bian, H.M. Effect of liguzinediol on ventricular remodeling in press-overloaded rats. Chin. Pharmacol. Bull. 2012, 28, 1699-1704.

12. Guo, Y.; Zhou, J.; Bian, H.M.; Zhu, Q.; Li, W.; Wu, Y. The effect of liguzinediol on hemodynamics in rats with acute heart failure induced by pentobarbital. Chin. J. Exp. Tradit. Med. Formulae 2012, $18,170-174$. 
13. Xu, Y.; Luo, Z.K; Liu, Q.M.; Huang, F.F.; Li, X.H.; Liu, L.; Li, W.; Chen, L. Positive inotropic mechanism of liguzinediol and heart safety evaluation. Chin. J. Pharmacol. Toxicol. 2012, 26, 151-156.

14. Wen, K.; Liu, Z.; Bian, H.M.; Li, W. Acute toxicity of liguzinediol. Chin. J. New Drugs Clin. Remedies 2011, 30, 234-235.

15. Li, W.; Chen, L.; Bian, H.M.; Wen, H.M.; Liu, Z. Application of 2,5-dihydroxymethyl3,6-dimethyl-pyrazine and its derivatives in pharmacy. U.S. Patent 8158630 B2, 17 April 2012.

16. Li, W.; Chen, L.; Bian, H.M.; Wen, H.M.; Liu, Z. Application of 2,5-dihydroxymethyl3,6-dimethyl-pyrazine and its derivatives in pharmacy. CN Patent ZL200810157140.4, 17 November 2010.

17. Zhang, L.; Li, W.; Wen, H.M.; Shan, C.X.; Bian, H.M. An LC-MS/MS method for determining liguzinediol in rat plasma and studying its pharmacokinetics. Chin. J. New Drugs 2013, 22, 1024-1046.

18. Shan, C.X.; Li, W.; Wen, H.M.; Wang, X.Z.; Zhu, Y.H.; Cui, X.B. Application of 2,5-dihydroxymethyl-3,6-dimethyl pyrazine and its derivatives in pharmacy. J. Pharm. Biomed. Anal. 2012, 62, 187-190.

19. Liu, Z.X.; Li, W.; Chen, L.; Wen, H.M.; Zhu, X.W. Synthesis and positive inotroic effect of methyl-substituted derivatives of liguzinediol. Chin. J. New Drugs Clin. Remedies 2014, 33, 357-363.

20. Chen, L.; Li, W.; Chen, L.; Liu, Z. Synthesis and positive inotropic effects of the secondary alcohol derivatives of liguzinediol. Chin. Pharm. J. 2013, 48, 1118-1122.

21. Ettmayer, P.; Amidon, G.L.; Clement, B.; Testa, B. Lessons learned from marketed and investigational prodrugs. J. Med. Chem. 2004, 47, 2393-2404.

22. Bonina, F.; Puglia, C.; Rimoli, M.G.; Avallone, L.; Abignente, E.; Boatto, G.; Nieddu, M.; Meli, R.; Amorena, M.; Caprariis, P.D. Synthesis and in vitro chemical and enzymatic stability of glycosyl 3'-azido-3'-deoxythymidine derivatives as potential anti-HIV agents. Eur. J. Pharm. Sci. 2002, 16, $167-174$.

23. Rautio, J.; Kumpulainen, H.; Heimbach, T.; Oliyai R.; Oh, D.; Järvinen, T.; Savolainen, J. Prodrugs: Design and clinical applications. Nat. Rev. Drug Discov. 2008, 7, 255-270.

24. Liu, Z.; Li, W.; Wen, H.M.; Bian, H.M.; Zhang, J.; Chen, L.; Chen, L.; Yang, K.D. Synthesis, biological evaluation, and pharmacokinetic study of novel LZDO prodrugs. Molecules 2013, 18, 4561-4572.

25. Simões, M.F.; Valente, E.; Gómez, J.R.; Anes, E.; Constantino, L. Lipophilic pyrazinoic acid amide and ester prodrugs. Eur. J. Pharm. Sci. 2009, 37, 257-263.

26. Høyemd, S.; Bruheim, S.; Mælandsmoa, G.; Standal, M.; Olberg, D.E.; Brudeli, B.; Åsberg, A.; Klaveness, J.; Rongvedd, P. Didanosine ester prodrugs: Synthesis, albumin binding properties and pharmacokinetic studies in rats. Eur. J. Med. Chem. 2009, 44, 3874-3879.

27. Vacondio, F.; Silva, C.; Lodola, A.; Carmi, C.; Rivara, S.; Duranti, A.; Tontini, A.; Sanchini, S.; Clapper, J.R.; Piomelli, D.; et al. Biphenyl-3-yl alkylcarbamates as fatty acid amide hydrolase (FAAH) inhibitors: Steric effects of $\mathrm{N}$-alkyl chain on rat plasma and liver stability. Eur. J. Med. Chem. 2011, 46, 4466-4473. 
28. Rai, B.J.; Liu, Z.D.; Liu, D.Y.; Lu, S.L.; Hider, R.C. Synthesis, physiochemical properties and biological evaluation of ester prodrugs of 3-hydroxypyridin-4-ones: Design of orally active chelators with clinical potential. Eur. J. Med. Chem. 1999, 34, 475-485.

29. Neises, B.; Steglich, W. Simple method for the esterification of carboxylic acids. Angew. Chem. Int. Ed. Engl. 1978, 17, 522-524.

30. Rautio, J.; Nevalainen, T.; Taipale, H.; Vepsalainen, J.; Gynther, J.; Pedersen, T.; Järvinen, T. Synthesis and In vitro Evaluation of aminoacyloxyalkyl esters of 2-(6-methoxy-2-naphthyl) propionic acid as novel naproxen prodrugs for dermal drug delivery. Pharm. Res. 1999, 16, $1172-1178$.

31. Turner, J.V.; Maddalena, D.J.; Agatonovic-Kustrin, S. Bioavailability Prediction Based on Molecular Structure for a Diverse Series of Drugs. Pharm. Res. 2004, 21, 68-82.

32. Yan, Y.D.; Sung, J.H.; Lee, D.W.; Kim, J.S.; Jeon, E.M.; Kim, D.D.; Kim, D.W.; Kim, J.O.; Piao, M.G.; Li, D.X.; et al. Evaluation of physicochemical properties, skin permeation and accumulation profiles of salicylic acid amide prodrugs as sunscreen agent. Int. J. Pharm. 2011, 419, 154-160.

33. Dias, C.S.; Anand, B.S.; Mitra, A.K. Effect of mono- and di-acylation on the ocular disposition of ganciclovir: Physicochemical properties, ocular bioreversion, and antiviral activity of short chain ester prodrugs. J. Pharm. Sci. 2001, 91, 660-668.

34. Shao, Z.; Park, G.B.; Krishnamoorthy, R.; Mitra, A.K. The physiochemical properties, plasma enzymatic hydrolysis, and nasal absorption of acyclovir and its 2'-ester prodrugs. Pharm. Res. 1994, 11, 237-242.

35. Lazzarato, L.; Donnola, M.; Rolando, B.; Chegaev, K.; Marini, E.; Cena, C.; Stilo, A.D.; Fruttero, R.; Biondi, S.; Ongini, E.; et al. (Nitrooxyacyloxy)methyl Esters of Aspirin as Novel Nitric Oxide Releasing Aspirins. J. Med. Chem. 2009, 52, 5058-5068.

36. National Research Council. Guide for the Care and Use of Laboratory Animals, 1st ed.; National Academy Press: Washington, DC, USA, 1996; pp. 21-25.

37. Yan, Y.D.; Kim, H.K.; Seo, K.H.; Lee, W.S.; Lee, G.S.; Woo, J.S.; Yong, C.S.; Choi, H.G. The Physicochemical Properties, in vitro Metabolism and Pharmacokinetics of a Novel Ester Prodrug of EXP3174. Mol. Pharm. 2010, 7, 2132-2140.

38. Anand, B.S.; Katragadda, S.; Mitra, A.K. Pharmacokinetics of novel dipeptide ester prodrugs of acyclovir after oral administration: Intestinal absorption and liver metabolism. J. Pharmacol. Exp. Ther. 2004, 311, 659-667.

39. Lipinski, C.A.; Lombardo, F.; Dominy, B.W.; Feeney, P.J. Experimental and computational approaches to estimate solubility and permeability in drug discovery and development settings. Adv. Drug Deliv. Rev. 2012, 64, 4-17.

Sample Availability: Samples of all the compounds are available from the authors.

(C) 2014 by the authors; licensee MDPI, Basel, Switzerland. This article is an open access article distributed under the terms and conditions of the Creative Commons Attribution license (http://creativecommons.org/licenses/by/4.0/). 